\title{
Obstacles on the information highway
}

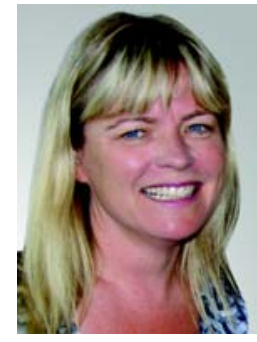

Ruth Armstrong Senior Deputy Editor

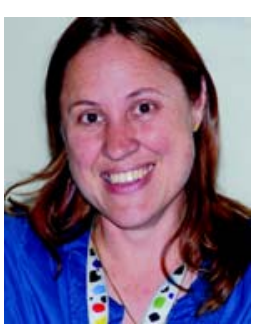

Ann Gregory Acting Editor

mja@mja.com.au

doi: 10.5694/mjal3.c0218 (a) he concept of monitoring and reporting on safety and quality in health care is not new. As Diane Watson, CEO of Australia's National Health

Performance Authority reminds us in this issue of the Journal (page 133), as early as 1860, Florence Nightingale called for the uniform collection of hospital statistics, so that outcomes could be compared "by hospital, region, and country" (Evid Based Nurs 2001; 4: 68-69).

In 2013, we are more able than ever to collect, interpret, share and act on such information, yet significant obstacles, some of which are explored by contributors to this issue of the Journal, remain.

Clinical registries of patient treatment and outcomes provide vital information to improve care, but they will only be credible if they are as complete as possible. Evans and colleagues say Australia is currently at a crossroads in the development of such registries, and needs to take the right path for them to be beneficial (page 134). They say the current approach of equating registries with research projects requiring multiple ethics committee approvals is inefficient, and that the "opt-in" arrangements of most registries result in low participation rates and the unethical exclusion of the most vulnerable people. Instead, they propose the formation of an umbrella registry to sign up to the National Health Information Agreement. Registries under this umbrella would need to meet stringent security and quality criteria and would be accredited in much the same way as pathology providers and hospitals.

The diversity of Australian general practice is generally something to celebrate but, unless data are collected with some consistency, they cannot be synthesised to guide future practice and policy. Britt and Miller, Director and Medical Director, respectively, of Australia's long-running Bettering the Evaluation and Care of Health (BEACH) program, voice concern that most electronic record systems used in general practice are unable to reliably link management actions to patient problems (page 125). This situation will hinder efforts to collect national information about the provision of care. Britt and Miller say this is unacceptable in this massive, expensive sector: in 20112012, there were 125 million general practice services provided to the community at a cost to government of about $\$ 5$ billion.

Without consistent, agreed diagnostic criteria, collections of clinical information will not be reliable enough to guide practice. Australia-wide data from the international Burden of Obstructive Lung Disease (BOLD) study suggest this could be a problem when it comes to the management of chronic obstructive pulmonary disease (COPD). Toelle and colleagues found that many of the participants who met the study's criteria for COPD had not been previously diagnosed (page 144). The researchers say this suggests greater effort is needed to make high-quality spirometry available in all health care settings. In an accompanying editorial, McDonald and Glasgow (page 124) point out that spirometry would also overturn inaccurate clinical diagnoses of COPD, thus minimising unnecessary treatment.

Of course, people - not data - are at the centre of our health care system. Gabbe and colleagues' qualitative research (page 149) neatly captures an aspect of care that the average clinical registry might miss: trauma patients' perspectives that their excellent acute hospital care was let down by a fragmented post-discharge outpatient experience. In the myriad statistics relating to the effectiveness of our health system, the experience of the people it exists to serve should not be forgotten.

As we overcome the obstacles to collecting quality information about our practice, another question arises: how should individual doctors respond to such information? Watson's advice is instructive: "Review the data to benchmark with your peer groups. Be open to learning from colleagues on how to achieve best performance, and be generous in sharing your innovations with the system."

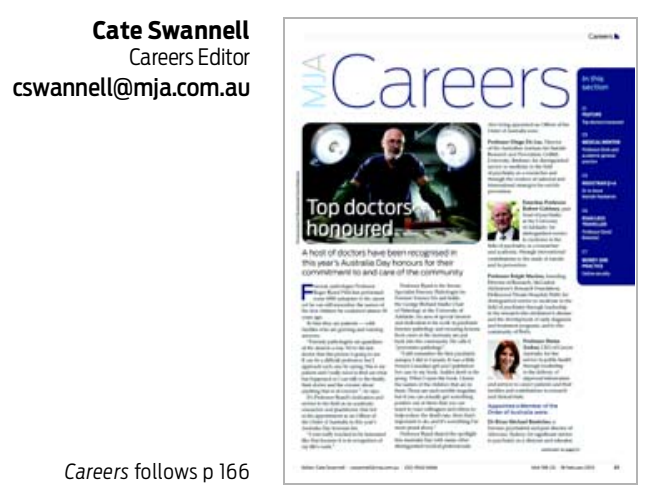

Careers follows $\mathrm{p} 166$

\section{Risk and rewards}

A host of doctors have been recognised in this year's Australia Day honours. Karen Burge spoke with forensic pathologist Professor Roger Byard about his 30 years of service and what his Order of Australia means to him (page C1). The recent hacking of a Gold Coast practice's medical records highlights the growing need for cyber security and insurance. Annabel McGilvray investigates in Money and Practice (page C7). Our Medical Mentor is Professor Doris Young, Chair of General Practice at the
University of Melbourne. She talks about the appeal of academic general practice and what inspires her. Dr Jo-Anne ManskiNankervis is the registrar under the spotlight and she talks about her diabetes research and the mentorship of Professor Young (page C5). In Road Less Travelled (page C6), Linda Drake speaks with Professor David Brewster, who is eschewing retirement for a posting in Dili where he will set up the first specialist postgraduate diploma course in paediatrics in East Timor. 